\title{
The Chemical Structure of Agar from Gracilaria compressa (C. Agardh) Greville, G. cervicornis (Turner) J. Agardh, G. damaecornis J. Agardh and G. domingensis Sonder ex Kützing (Gigartinales, Rhodophyta)
}

\author{
M. Lahaye ${ }^{1}$ and W. Yaphe ${ }^{2}$ \\ McGill University, Department of Microbiology and Immunology, 3775 University Street, H3A 2 B4 Montreal, \\ Canada
}

(Accepted 24 March 1989)

\begin{abstract}
The chemical structure of agar fractions obtained from Gracilaria compressa, G. cervicornis, G. damaecornis and $G$. domingensis with a sequential solvent extraction has been determined by ${ }^{13} \mathrm{C}-\mathrm{NMR}$ spectroscopy. Gracilaria compressa agar consists of agarobiose, pyruvated agarobiose and a low concentration of 6-Omethylated agarobiose repeating units; G. cervicornis and $G$. domingensis agars are composed of 6-O-methylated agarobiose, agarobiose-6-sulfate, agarobiose, and a repeating unit with 4-O-methyl- $\alpha$-L-galactose; finally, $G$. damaecornis agar is made of the same repeating units of the latter agars plus agarobiose-4-sulfate. From these four algae, a fraction enriched with pyruvated or sulfated repeating units was obtained in water at room temperature. An extract essentially composed of only 6-O-methylated agarobiose repeating units was obtained from the Gracilaria species with boiling $80 \%$ ethanol. The concentration of the methylated repeating unit decreased in the subsequent boiling in $60 \%$ and $40 \%$ ethanol extracts and in the hot water extract $\left(121^{\circ} \mathrm{C}\right)$, whereas charged repeating units were present in these agar fractions. Floridean starch contaminated the hot water extract.
\end{abstract}

The combination of sequential solvent extraction and ${ }^{13} \mathrm{C}-\mathrm{NMR}$ represents a convenient approach in determining the chemical heterogeneity of agar.

\section{Introduction}

Marine red algae belonging to the genus Gracilaria represent an important potential source for the industrial production of agar and agarose (McLachlan 1985). Although the rheological properties of most Gracilaria agar gels are usually far from those required for biotechnological applications (electrophoresis, chromatographies, ...), they are generally suitable for the food industry. In fact, the rheological properties reflect the chemical variations of the basic repeating disaccaride, agarobiose (Araki 1966, Rees 1969 and Fig. 1), that compose the family of polysaccharides in agar (Duckworth and Yaphe 1971, Izumi 1970,

\footnotetext{
${ }^{1}$ Present address: INRA-LBTG, B. P. 527 rue de la Géraudière, 44026 Nantes Cedex 03, France

2 Deceased, May 1986
}

Lahaye et al. 1986) and probably also the molecular weight of the different agarose molecules in agar (Rochas and Lahaye 1989 a).

Species, strain, and growth conditions of Gracilaria affect the chemical heterogeneity of agar (Lahaye and Yaphe 1988 and references herein) and thus, these important factors have to be taken into account when harvesting algae for the production of commercially suitable agar. Different methods are available for assessing the chemical structure of agars but probably, nuclear magnetic resonance (NMR) spectroscopy is the fastest and most reliable one. Recently, solid-state (CP-MAS) ${ }^{13} \mathrm{C}-\mathrm{NMR}$ spectroscopy has been used succesfully to distinguished between agar and carrageenan structures as well as some of their substituent groups in dry pieces of seaweeds (Rochas and Lahaye $1989 \mathrm{~b}$ ). In this paper, the chemical structure of 


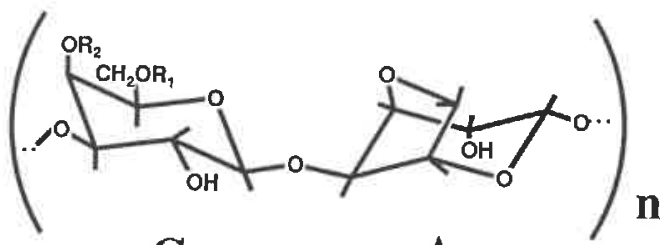

A

G

A

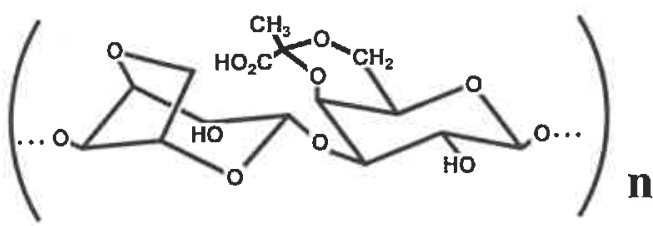

$A^{-}$

Fig. 1. Structure of the agarobiose and substituted agarobiose repeating units:

A. agarobiose: $R_{1}=R_{2}=H$; A: 3,6-anhydro- $\alpha$-L-galactopyranose, $\mathrm{G}$ : $\beta$-D-galactopyranose.

agarobiose-6-sulfate: $\mathrm{R}_{1}=\mathrm{SO}_{3}, \mathrm{R}_{2}=\mathrm{H} ; \mathrm{A}^{+}:$3,6-anhydro$\alpha$-L-galactopyranose, $\mathrm{G}^{+}: \beta$-D-galactopyranose-6-sulfate. agarobiose-4-sulfate: $\mathrm{R}_{1}=\mathrm{H}, \mathrm{R}_{2}=\mathrm{SO}_{3} ; \mathrm{A}^{0}: 3,6$-anhydro$\alpha$-L-galactopyranose, $\mathrm{G}^{\circ}: \beta$-D-galactopyranose-4-sulfate. 6-O-methyl agarobiose: $\mathrm{R}_{1}=\mathrm{CH}_{3}, \mathrm{R}_{2}=\mathrm{H}$; $\mathrm{G}^{\prime}$ : 6-Omethyl- $\beta$-D-galactopyranose.

proposed branched repeating unit (Hirase et al. 1983); $\mathrm{R}_{1}=4$-O-methyl- $\alpha$-L-galactopyranose, $\mathrm{R}_{2}=\mathrm{H}$; $\mathrm{B}$ : 4-Omethyl- $\alpha$-L-galactopyranose.

B. pyruvated agarobiose; $\mathrm{G}^{-}$: $(4,6$, carboxyethylidene $)-\beta$-D-galactopyranose, $A^{-}: 3,6$-anhydro- $\alpha$-L-galactopyranose.

charged agars extracted from Gracilaria compressa (C. agardh) Greville, G. cervicornis (Turner) J. Agardh, G. damaecornis J. Agardh, and G. domingensis Sonder ex Kützing previously reported by Duckworth $e t$ al. (1971), were re-investigated using the sequential solvent extraction described by Lahaye et al. (1986) and ${ }^{13} \mathrm{C}-\mathrm{NMR}$ spectroscopy. These methods permitted the isolation and characterization of novel agar fractions. The fine chemical structure of the substituted agarobiose repeating units encountered in these fractions is described in more detail elsewhere (Lahaye et al. 1989).

\section{Material and Methods}

Gracilaria cervicornis (Turner) J. Agardh (referred to as G. ferox by Hong et al. 1969 and Duckworth et al. 1971), G. damaecornis J. Agardh, G. domingensis Sonder ex Kützing, and G. compressa (C. Agardh) Greville samples were those investigated by Hong et al. (1969) and Duckworth et al. (1971). Agar extraction from these algae followed the procedure described by Lahaye et al. (1986) with the following modifications: the dry algal pieces $(10 \mathrm{~g})$ were left at

room temperature with stirring for 4 hours or overnight in $95 \%$ ethanol $(300 \mathrm{ml})$, the pigmented extract was discarded and the algal pieces extracted with boiling $95 \%$ ethanol as described by Lahaye et al. (1986); the boiling $20 \%$ ethanol and hot water $\left(100{ }^{\circ} \mathrm{C}\right)$ extracts were omitted. ${ }^{13} \mathrm{C}$-NMR spectroscopy was carried out using a Bruker WH 400 operating at $100.6 \mathrm{MHz}$. Spectra of about $5 \%$ polysaccharide solution in $\mathrm{D}_{2} \mathrm{O}$ were recorded at $80^{\circ} \mathrm{C}$ with a spectral width of $10-18 \mathrm{KHz}$ and relaxation delay of 0.5 to $0.7 \mathrm{~s}$. Carbon chemical shifts were measured in parts per million relative to internal dimethyl sulfoxide and converted to values related to tetramethylsilane (conversion constant: 39.6 ).

\section{Results and Discussion}

The yields of agar extracted with cold water $\left(22^{\circ} \mathrm{C}\right)$, boiling 80,60 , and $40 \%$ ethanol, and hot water $\left(121^{\circ} \mathrm{C}\right)$ are depicted in Figure 2. The total recovery of polymers on the basis of algal dry weight was 42.3 , $37.2,39.2$, and $41.5 \%$ for Gracilaria cervicornis, $G$. damaecornis, G. domingensis, and G. compressa, respectively. Major fractions of agar were recovered with boiling $60,40 \%$ ethanol and hot water $\left(121^{\circ} \mathrm{C}\right)$ (Fig. 2) except for $G$. domingensis for which the yield of the cold water extract was greater than that of the $40 \%$ ethanol extract (Fig. 2C).
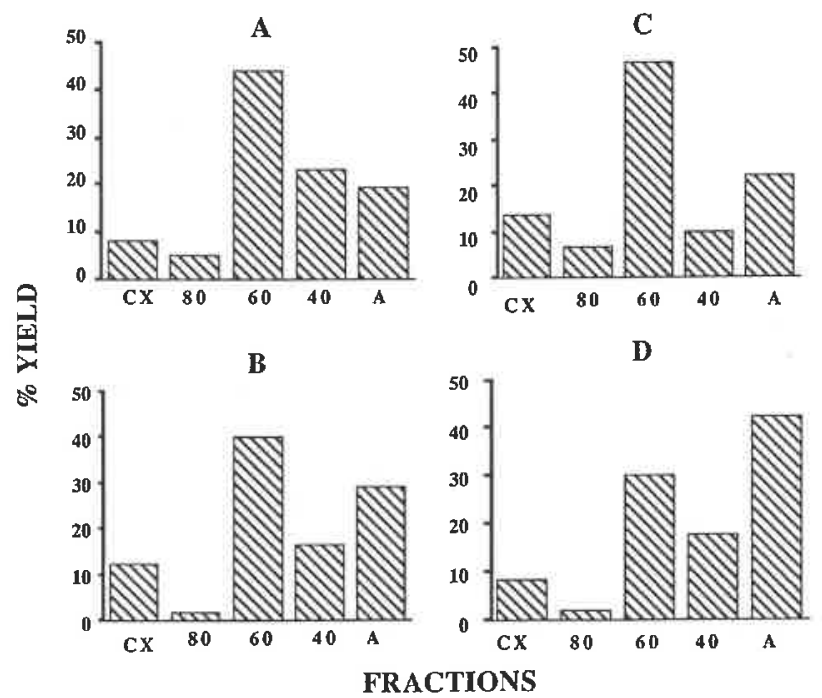

Fig. 2. Yields of agar extracted from A, Gracilaria cervicornis, $\mathrm{B}, G$. damaecornis, C, G. domingensis, D, G. compressa with water at $22{ }^{\circ} \mathrm{C}(\mathrm{CX})$, boiling $80,60,40 \%$ ethanol-water mixtures, and water at $121^{\circ} \mathrm{C}$ (Auto). The yield in each extract represents a percentage of the dry weight of total agar extracted from the alga.

Fig. $3 .{ }^{13} \mathrm{C}-\mathrm{NMR}$ spectrum of agar fractions extracted from G. cervicornis with water at $22^{\circ} \mathrm{C}(\mathrm{CX})(1960$ transients), boiling 80 , $60,40 \%$ ethanol-water mixture $\left(779,1116,1132\right.$ transients, respectively) and water at $121{ }^{\circ} \mathrm{C}$ (A, 2519 transients). The letters represent carbons in the agarobiose or substituted agarobiose depicted in Figure 1; $\mathrm{C}$ refers to carbons in starch; 4- and 6-O-CH refer to the methyl carbon in 4-O-methyl- $\alpha$-L-galactose and 6-O-methyl- $\beta$-D-galactose, respectively. 

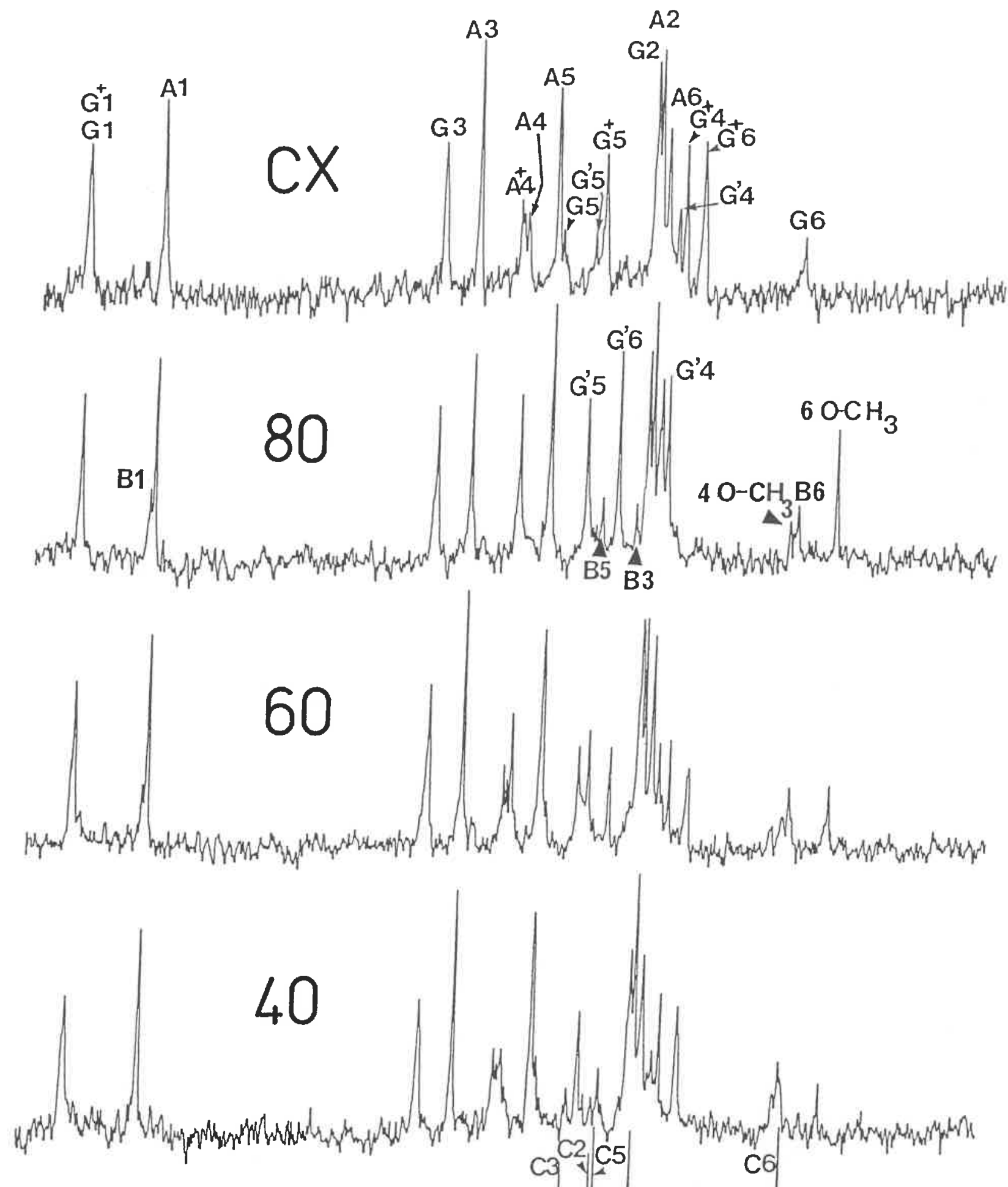

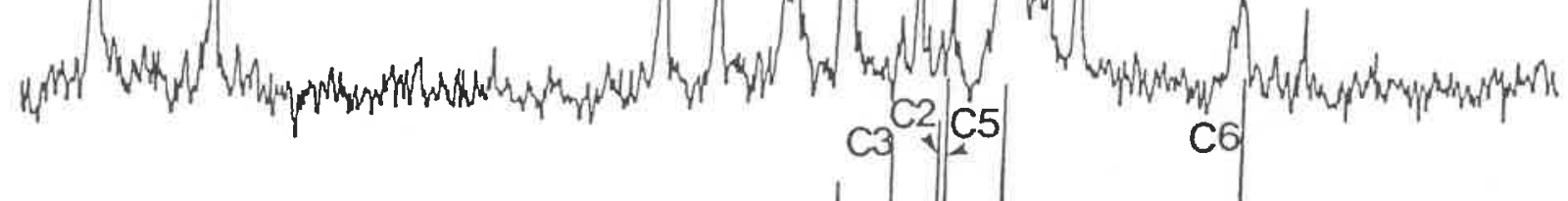

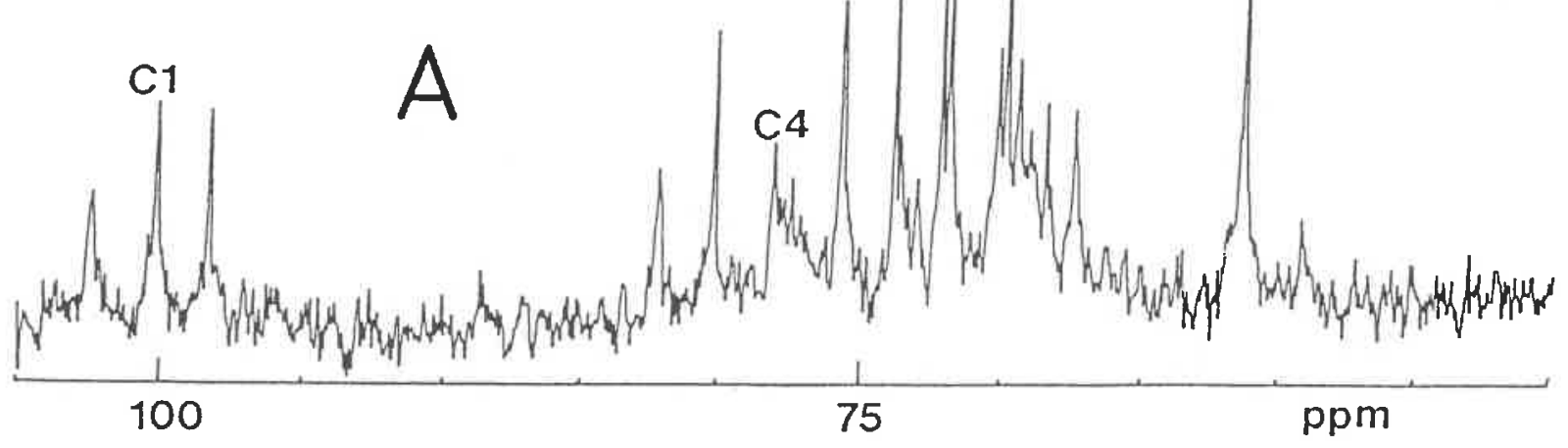


The ${ }^{13} \mathrm{C}$-NMR spectra of all fractions extracted from these algae confirmed the agar-type structure of the polysaccharides and demonstrated the presence of peculiarly substituted agarobiose repeating units.

Gracilaria cervicornis cold water extract showed a spectrum typical of agar essentially composed of repeating units containing D-galactose-6-sulfate $\left[\mathrm{G}^{+} 1\right.$ : 102.6, 102.4; $\mathrm{G}^{+} 4: 68.4 ; \mathrm{G}^{+} 5: 73.0 ; \mathrm{G}^{+} 6: 67.4 ; \mathrm{A}^{+} 4$ : 77.8, 77.6 ppm; Fig. 3 (CX); Usov et al. 1983] with split signals for $\mathrm{G}^{+} 1$ and $\mathrm{A}^{+} 4$ probably resulting from a non-uniform distribution of the sulfated repeating units in the polymers. Signal splittings have already been observed for agar with repeating units containing L-galactose-6-sulfate replacing 3,6-anhydrogalactose and believed to be the biological precursor to the agarobiose repeating unit (Lahaye et al. 1988 a, Morrice et al. 1983, Rees 1961). Small signals were observed for agarobiose (A, G, Usov et al. 1980, Rochas et al. 1986), and for 6-O-methylated agarobiose ( $\mathrm{G}^{\prime}$, Nicolaisen et al. 1980). But, in contrast to the previously reported composition of cold water soluble agar (Lahaye and Yaphe 1988, Lahaye et al. 1986), no signal was detected for the biological precursor disaccharide unit.

The $80 \%$ ethanol extract agar from G. cervicornis had a quite different spectrum from that of the preceeding fraction since it was typical of polymers composed essentially of 6-O-methylated agarobiose [Fig. 3 (80), $\mathrm{G}^{\prime}, \mathrm{O}-\mathrm{CH}_{3}$ ]. Small signals at $98.6,70.8$, and $61.9 \mathrm{ppm}$ were attributed to the 4-O-methyl- $\alpha$-L-galactose (Lahaye et al. 1988) known to be present in this agar (Hong et al. 1969, Duckworth et al. 1971, Bird et al. 1987) and probably occurring as a branch as proposed for Laurencia agar (Hirase et al. 1983). No signal was detected for unsubstituted agarobiose repeating units. The spectrum of the $60 \%, 40 \%$ ethanol and hot water extracts from that alga showed signals attributed to agar essentially composed of a combination of four types of repeating units: 6-O-methylated agarobiose, agarobiose containing D-galactose-6-sulfate, unsubstituted agarobiose, and a minor content of repeating unit containing 4-O-methyl- $\alpha$-L-galactose [Fig. 3, (60, $40,0)]$. These fractions differed in the concentration of 6-O-methylated agarobiose, the highest signal intensity associated with this substituent being observed on the spectrum of the $60 \%$ ethanol extract. Signals for floridean starch were also observed (Fig. 3, C; Dais and Perlin 1982, Lahaye et al. 1986) and this polysaccharide accounted for about $51 \%$ of the hot water extract, as determined from the integral of the anomeric signals, C1 (100.4, $100.2 \mathrm{ppm}), \mathrm{G} 1$ (102.5 $\mathrm{ppm})$ and $\mathrm{A} 1$ (98.4 ppm). Other small signals, bearly exceeding the noise level on these spectra, remain unassigned.

The ${ }^{13} \mathrm{C}-\mathrm{NMR}$ spectra of agar fractions extracted from $G$. domingensis were similar to those of G. cervicornis (data not shown). Small signals for repeating units containing D-galactose-6-sulfate were observed on the spectrum of the $80 \%$ ethanol extract. Floridean starch accounted for about $30 \%$ of the hot water extract.

Another peculiar substituted agarose was that from G. damaecornis (Fig. 4). The spectrum of the cold water extract [Fig. 4 (CX)] showed major signals typical of polymers composed of agarobiose containing D-galactose-6-sulfate $\left(\mathrm{G}^{+}, \mathrm{A}^{+}\right)$and agarobiose containing D-galactose-4-sulfate $\left(A^{\circ} 1: 96.8, G^{\circ} 2: 71.0\right.$, $\mathrm{G}^{\circ} 3: 80.0, \mathrm{G}^{\circ} 4: 77.0, \mathrm{G}^{\circ} 5: 75.0, \mathrm{G}^{\circ} 6: 61.3 \mathrm{ppm}, \mathrm{La}-$ haye et al. 1988 a). Again, no signal was detected for the biological precursor to the agarobiose repeating unit.

In contrast, the $80 \%$ ethanol extract [Fig. 4 (80)] showed major NMR signals typical of 6-O-methylated agarobiose repeating units $\left(\mathrm{G}^{\prime}, \mathrm{O}-\mathrm{CH}_{3}\right)$ and small signals at $102.6,77.6,73.0,68.4$, and $67.4 \mathrm{ppm}$ attributed, respectively, to $\mathrm{G}^{+} 1, \mathrm{~A}^{+} 4, \mathrm{G}^{+} 5$, and $\mathrm{G}^{+} 6$ of agarobiose repeating units containing $\mathrm{D}$-galactose6-sulfate. No signal was detected for agarobiose repeating unit.

The $60 \%, 40 \%$ ethanol and hot water extracts [Fig. 4 $(60,40,0)]$ showed complex NMR spectra. Signals were attributed to agar composed of repeating units containing D-galactose-6-sulfate, 6-O-methyl-D-galactose, D-galactose-4-sulfate, and 4-O-methyl- $\alpha-\mathrm{L}-$ galactose. As for $G$. cervicornis, these fractions differed in their content of 6-O-methylated agarobiose. Signals for floridean starch were observed and this reserve polysaccharide accounted for about $19 \%$ of the hot water extract as roughly estimated from the integral of the anomeric signals.

Finally, the ${ }^{13} \mathrm{C}$-NMR spectra of $G$. compressa agar fractions demonstrated the presence of pyruvate group on agarobiose repeating units. The spectrum of the cold water extract [Fig. $5(\mathrm{CX})$ ] showed typical signals associated with agar composed of agarobiose $(A, G)$ and pyruvated agarobiose repeating units (A-2: 70.0, $A^{-4}$ : 77.5, $\mathrm{G}^{-1}$ : 102.2, $\mathrm{G}^{-3}$ : 79.5, $\mathrm{G}^{-} 4$ : Fig. 4. ${ }^{13} \mathrm{C}-\mathrm{NMR}$ spectrum of agar fractions extracted from $G$. damaecornis with water at $22{ }^{\circ} \mathrm{C}(\mathrm{CX})(1200$ transients), boiling
80, 60, $40 \%$ ethanol-water mixture $\left(1159,800,1721\right.$ transients, respectively) and water at $121{ }^{\circ} \mathrm{C}(\mathrm{A}, 2565$ transients). The letters represent carbons in the agarobiose or substituted agarobiose depicted in Figure $1 ; \mathrm{C}$ refers to carbons in starch; $4-$ and $6-\mathrm{O}-\mathrm{CH}_{3}$ refer to the methyl carbon in 4-O-methyl- $\alpha$-L-galactose and $6-\mathrm{O}$-methyl- $\beta$-D-galactose, respectively. 
G G1 $^{+} \quad$ A1<smiles></smiles>

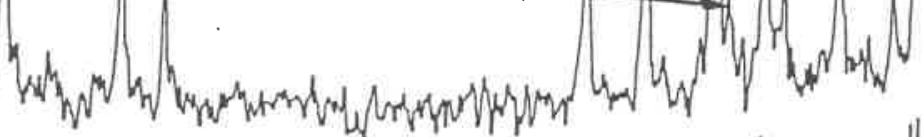

180

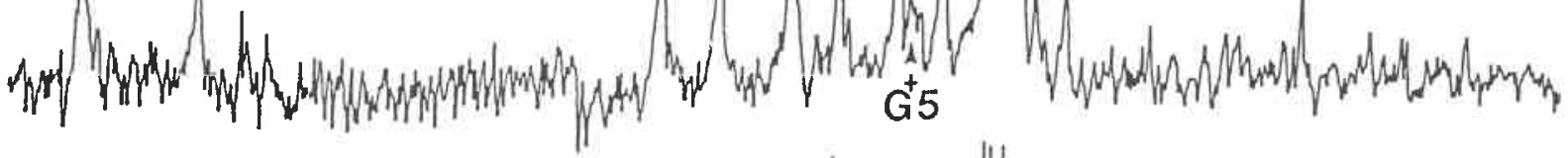

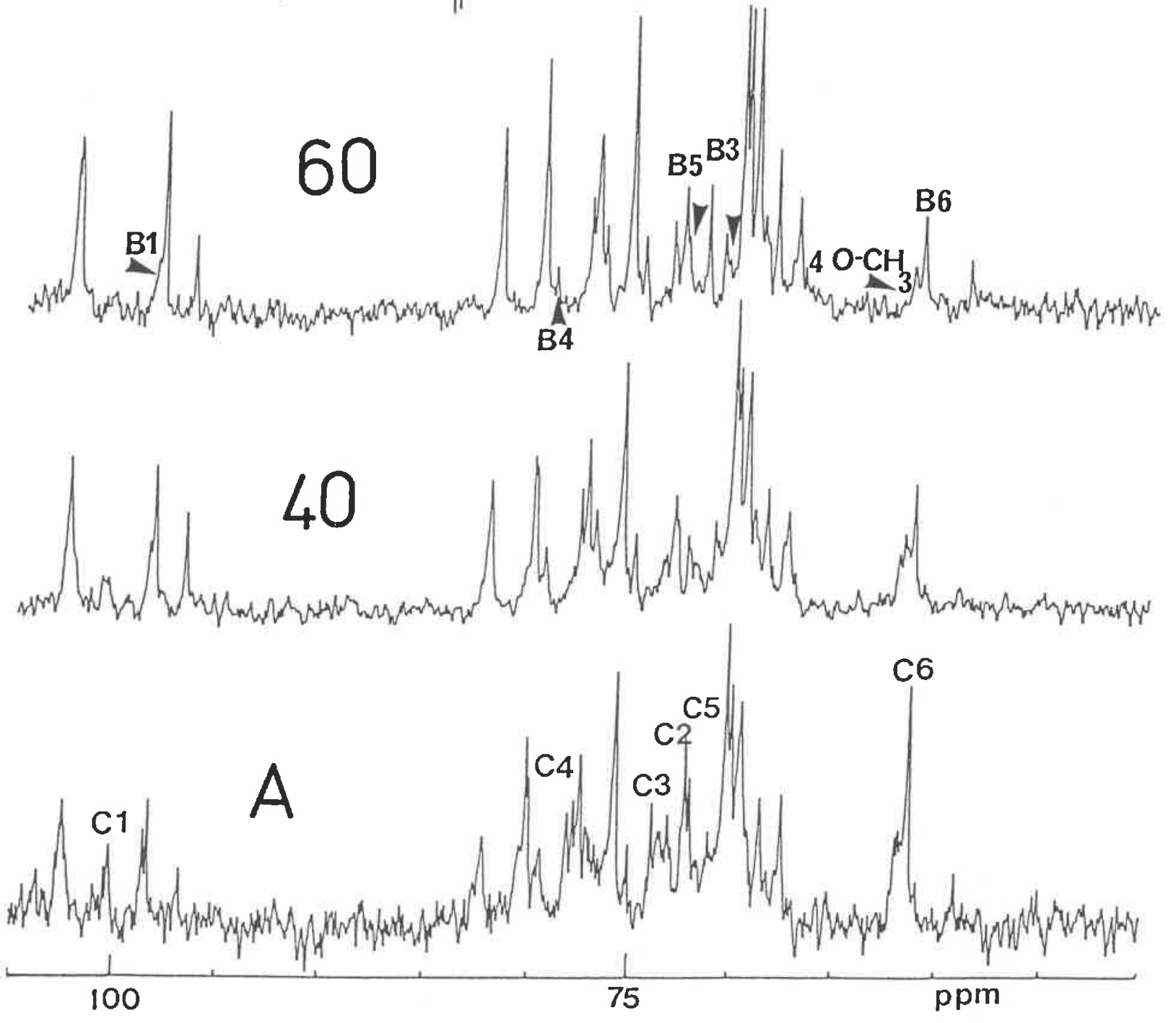


71.6, $\mathrm{G}^{-} 5: 66.7, \mathrm{G}^{-} 6: 65.3, \mathrm{C}^{-} \mathrm{CH}_{3}: 25.7, \mathrm{COOH}$ : $176.3 \mathrm{ppm}$, Lahaye et al. 1989). The relaxation time of the quaternary carbon of the pyruvate ketal was probably too long to give a signal under the spectral conditions used. No signal was detected for a repeating unit containing L-galactose-6-sulfate.

The $80 \%$ ethanol extract was determined from its ${ }^{13} \mathrm{C}$ NMR spectrum to be composed essentially of agarobiose and 6-O-methylated agarobiose repeating units [Fig. 5 (80), G']. The signal for the methyl group of the methylated disaccharide repeating unit was not observed probably due to the spectral acquisition conditions.

The $60 \%$ and $40 \%$ ethanol extracts [Fig. $5(60,40)$ ] showed major NMR signals attributed to agar polymers constituted of agarobiose and pyruvated agarobiose repeating units. Methylated agarobiose repeating units were not detected.

The ${ }^{13} \mathrm{C}-\mathrm{NMR}$ spectrum of the hot water extract [Fig. 5(A)] showed signals demonstrating the presence in this fraction of a combination of agar and floridean starch. The latter accounted for $19 \%$ of the fraction, as estimated from the integral of the anomeric signals. The agar was mainly constituted of agarobiose and a low concentration of pyruvated agarobiose. The ratio of agarobiose to pyruvated agarobiose estimated from the integral of $\mathrm{G}^{5}$ and $\mathrm{G}^{-5}$ was lower than that of the other fractions (except the $80 \%$ ethanol extract). It was of $1: 0.1$ as compared to $1: 0.3$ in fraction 40 , $1: 0.4$ in fraction 60 , and $1: 0.7$ in fraction CX. The observation of agar having a low degree of pyruvation agrees with the results of Duckworth and Yaphe (1971) and Young et al. (1971) that demonstrated that pyruvation occurs on a peculiar family of agar in the alga. The biological significance of the pyruvated agarobiose distribution in $G$. compressa agar remains to be established. Other small signals bearly exceeding the noise level on the spectrum remain unassigned.

Sequential extraction of agar from algae has been interpreted to reflect the solubility and association of polysaccharides in the algal cell-wall (Lahaye et al. 1986) and is not directly related to the weight-average molecular weight of the molecules (Rochas and Lahaye 1989 a). Thus, high concentrations of methoxyl and 3,6-ahydrogalactose in agar increase the hydrophobic properties of the molecules, allowing for their solubility in hot solutions of alcohol $(40-80 \%$ boiling ethanol). In contrast, substitution of agarobiose with alkali-stable charged groups increases hydrophilic properties with concomitant solubility of agar in polar solvents (rich in water). Furthermore, the replacement of anhydrogalactose by L-galactose-6-sulfate in the agarobiose introduces irregularity into the agarose helical structure (Arnott et al. 1974) and decrease the associations between polymers. In addition, the temperature at which agaroses are soluble is related to the conformation of the molecules and thus, to their non-covalent association between each other like in a gel. However, covalent cross-linkages between agaroses and other cell-wall polymers are suspected and are believed to modify the solubility of these molecules in requiring harsh conditions (water at $121^{\circ} \mathrm{C}$ ) for their extraction (Lahaye et al. 1988). The present results confirm that any high concentration of substituent groups disrupting the agarose helical conformation, and thus aggregation, such as sulfate and pyruvate, increases the solubility of the molecules, particularly in water at room temperature.

The present extraction method allowed for the solubilization of novel agar fractions such as highly sulfated agar containing D-galactose-4-sulfate and/or Dgalactose-6-sulfate such as the cold water extract from G. cervicornis, G. damaecornis, and G. domingensis. The sulfated galactose residues were estimated from the integral of ${ }^{13} \mathrm{C}$-NMR signals to represent $60-$ $90 \%$ of the D-galactose residues in these agars (about $16-25 \%$ sulfate on a weight basis). Although these values are comparable to those obtained from Gloiopeltis agar (Hirase and Watanabe 1971, Penman and Rees 1973), this is the first report of highly sulfated (alkali-stable) agar extracted from Gracilaria species.

Similarly, a highly pyruvated agar was obtained in the cold water extract from $G$. compressa. The concentration of pyruvated agarobiose in this agar $(44 \%)$, estimated from the integrals of ${ }^{13} \mathrm{C}$-NMR signals, is approximatively equivalent to 3 times $(9.4 \%$ pyruvic acid on a weight basis) the concentration $(2.8 \%$ on a weight basis) reported by Duckworth et al. (1971) and Young et al. (1971) from native G. compressa agar.

Several attempts have been made to correlate chemical structure to taxonomy of algae (Gretz et al. 1986 and references herein, Bird et al. 1987). The presence of D-galactose-6-sulfate in agar extracted from $G$. cervicornis and $G$. domingensis, the presence of pyruvated agarobiose repeat unit in G. compressa agar, and particularly, the regular distribution of galactose-

Fig. 5. ${ }^{13} \mathrm{C}$-NMR spectrum of agar fractions extracted from $G$. compressa with water at $22{ }^{\circ} \mathrm{C}(\mathrm{CX})(793$ transients), boiling 80 , $60,40 \%$ ethanol-water mixture $\left(2080,1397,1705\right.$ transients, respectively) and water at $121^{\circ} \mathrm{C}(\mathrm{A}, 2120$ transients). The letters represent carbons in the agarobiose or substituted agarobiose depicted in Figure 1; C refers to carbons in starch. 

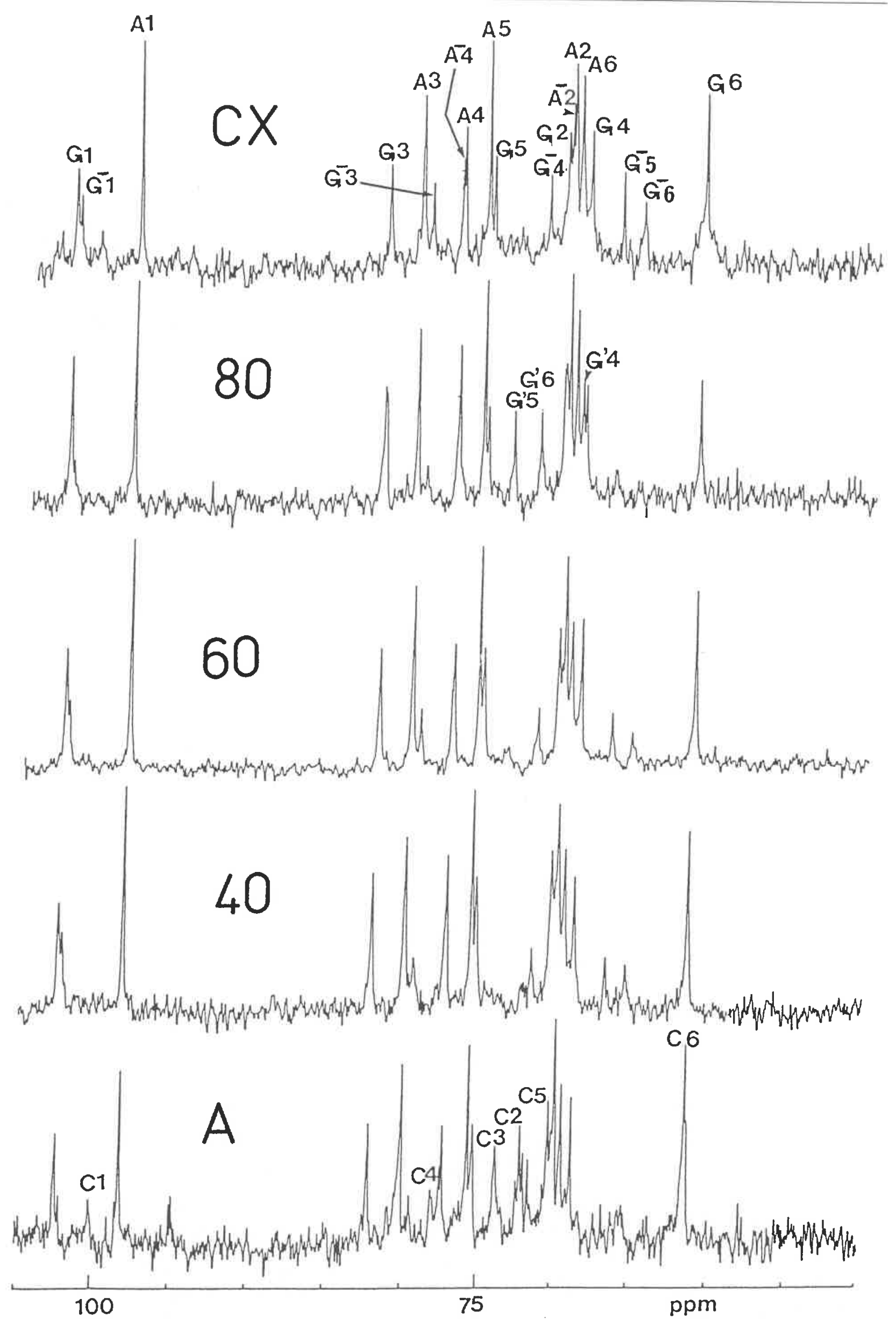
4-sulfate in $G$. damaecornis agar (on average 4 repeating units contains D-galactose-4-sulfate per 10 repeating units containing D-galactose-6-sulfate or 6O-methyl-galactose), may be characteristic of these species. It should also be noted that it is the first report of D-galactose-4-sulfate occurring as a major sugar in agar.

Observation of ${ }^{13} \mathrm{C}-\mathrm{NMR}$ signals in spectra of agar fractions from $G$. servicornis, $G$. damaecornis, and $G$. domingensis attributed to 4-O-methyl- $\alpha$-L-galactose occurring probably as a branch of the agarobiose repeating unit is in agreement with the thin layer chromatographic results of Duckworth et al. (1971) and with the pyrolysis-mass spectrometry data of Bird et al. (1987). Methylation is known to increase the gelling temperature of agars (Guiseley 1970); further work is now needed to determine the physico-chemical and rheological effects of this masking group in agar.

Physiological conditions are known to affect the growth rate of the algae and also the concentration of certain chemical structure in Gracilaria agar (Lahaye and Yaphe 1988). The present analyses were carried out on single samples and thus did not reflect the possible changes in concentration of substituent groups. A particularly important masked structure in agar which has not been observed here, is L-galactose- 6-sulfate since it has been proposed to be the biological precursor to the 3,6-anhydrogalactose residue (Rees 1961) and most probably reflects the growth status of of the algae.

In conclusion, Gracilaria agar consists of a variety of related hybrid molecules varying in the extent and types of substituted repeating units. The chemical heterogeneity of these polysaccharides is conveniently determined using the combination of sequential solvent extraction and ${ }^{13} \mathrm{C}-\mathrm{NMR}$ spectroscopy. The latter extraction procedure should prove useful together with anion exchange chromatography in isolating particular molecules to be used as models in the study of the physical and rheological properties of agarose.

\section{Acknowledgements}

This work was supported by a grant from the Natural Sciences and Engineering Research Council of Canada. The authors thank Dr Phan Viet and Ms. Bilodeau for technical assistance and for use of the NMR facilities at the Laboratoire de Résonance Magnétique Nucléaire à Haut Champ, Université de Montréal, Canada; and Dr Rochas for the helpful criticism of the manuscript.

\section{References}

Araki, C. 1966. Some recent studies on the polysaccharides of agarophytes. Proc. Int. Seaweed Symp. 5: 3-17.

Arnott, S. A., A. Fulmer, W. E. Scott, I. C. M. Dea, R. Moorhouse and D. A. Rees. 1974. Agarose double helix and its function in agarose gel structure. J. Mol. Biol. 90 $269-284$.

Bird, C. J., R. J. Helleur, E. R. Hayes and J. McLachlan. 1987 Analytical pyrolysis as a taxonomic tool in Gracilaria (Rhodophyta: Gigartinales). Proc. Int. Seaweed Symp. 12: 207212

Dais, P. and A. S. Perlin. 1982. High field, ${ }^{13} \mathrm{C}-\mathrm{NMR}$ spectroscopy of $\beta$-glucans, amylopectin, and glycogen. Carbohydr. Res. 100: 103-116.

Duckworth, M., K. C. Hong and W. Yaphe. 1971. The agar polysaccharides of Gracilaria species. Carbohydr. Res. 18: $1-19$.

Duckworth, M. and W. Yaphe. 1971. The structure of agar. Part 1: Fractionation of a complex mixture of polysaccharides. Carbohydr. Res. 16: 189-197.

Gretz, M. R., J. M. Aronson and M. R. Sommerfeld. 1986. Cell wall composition of the conchocelis phases of Bangia atropurpurea and Porphyra leucosticta (Rhodophyta). Bot. Mar. 29: 91-96.

Guiseley, K. B. 1970. The relationship between methoxyl content and gelling temperature of agarose. Carbohydr. Res. 13: $247-256$.

Hirase, S. and K. Watanabe. 1971. Fractionation and structural investigation of funoran. Proc. Int. Seaweed Symp. 7: 451454.
Hirase, S., K. Watanabe, R. Tanako and J. Tamura. 1983. Structural features of the sulfated polysaccharides isolated from the red seaweed Laurencia undulata. Abstr. Int. Seaweed Symp., 11th, Inst. of Oceanology, Academia Sinica, Quingdao, People's Republic of China, p. 93.

Hong, K. C., M. E. Goldstein and W. Yaphe. 1969. A chemical and enzymatic analysis of the polysaccharides from Gracilaria. Proc. Int. Seaweed Symp. 6: 473-482.

Izumi, K. 1970. A new method for fractionation of agar. $\mathrm{Agr}$. Biol. Chem. 34: 1739-1740.

Lahaye, M., J. F. Revol, C. Rochas, J. McLachlan and W. Yaphe. 1988. The chemical structure of Gracilaria crassissima (P. et H. Crouan in Schramm et Mazé) P. et H. Crouan in Schramm et Mazé and G. tikvahiae McLachlan (Gigartinales, Rhodophyta) cell wall polysaccharides. Bot. Mar. 31: $491-501$.

Lahaye, M., C. Rochas and W. Yaphe. 1986. A new procedure for determining the heterogeneity of agar polymers in the cell walls of Gracilaria spp. (Gracilariaceae, Rhodophyta). Can. J. Bot. 64: 579-585.

Lahaye, M. and W. Yaphe. 1988. Effects of seasons on the chemical structure and gel strength of Gracilaria pseudovernucosa agar (Gracilariaceae, Rhodophyta). Carbohydr. Polym. 8: 285-301.

Lahaye, M., W. Yaphe, M. T. Phan Viet and C. Rochas. 1989. ${ }^{13} \mathrm{C}$ nuclear magnetic resonance investigation of methylated and charged agarose oligosaccharides and polysaccharides. Carbohydr. Res. in press.

McLachlan, J. 1985. Macroalgae (seaweeds): industrial resources and their utilization. Plant and Soil 89: 137-157. 
Morrice, L. M., M. W. McLean, W. F. Long and F. B. Williamson. 1983. Porphyran primary structure. An investigation using $\beta$-agarase I from Pseudomonas atlantica and ${ }^{13} \mathrm{C}$ NMR spectroscopy. Eur. J. Biochem. 133: 673-684.

Nicolaisen, F. M., I. Meyland and K. Schaumburg. $1980 .{ }^{13} \mathrm{C}-$ NMR spectra at $67.9 \mathrm{MHz}$ of agarose solutions and partly 6-O-methylated agarose at $95^{\circ} \mathrm{C}$. Acta. Chem. Scand. Ser. B 34: 103-107.

Penman, A. and D. A. Rees. 1973. Carrageenans. Part IX. Methylation analysis of galactan sulphates from Furcellario fastigiata, Gigartina canaliculata, Gigartina chamissoi, Gigartina atropurpurea, Ahnfeltia durvellaei, Gymnogongrus furcellatus, Eucheuma isoforme, Eucheuma uncinatum, Aghardhiella tenera, Pachymenia hymantophora, and Gloiopeltis cervicornis. Structure of \&-carrageenan. J. Chem. Soc. (Perkin 1): $2182-2187$.

Rees, D. A. 1961 . Enzymatic synthesis of the 3,6-anhydro-Lgalactose within porphyran from L-galactose-6-sulphate units. Biochem. J. 81: $347-352$.
Rees, D. A. 1969. Structure, conformation and mechanism in the formation of polysaccharide gels and networks. $A d$ vances Carbohydr. Chem. Biochem. 24: 267-332.

Rochas, C. and M. Lahaye. 1989 a. Average molecular weight and molecular weight distribution of agarose and agarose type polysaccharides. Carbohydr. Polymers. In press.

Rochas, C. and M. Lahaye. 1989 b. Solid state ${ }^{13} \mathrm{C}-\mathrm{NMR}$ spectroscopy of red seaweeds, agars and carrageenans. Carbohydr. Polymers. In press.

Rochas, C., M. Lahaye, W. Yaphe and M. T. Phan Viet. 1986. ${ }^{13} \mathrm{C}-\mathrm{NMR}$-spectroscopic investigation of agarose oligomers. Carbohydr. Res. 148: 199-207.

Usov, A. I., E. G. Ivanova and A. S. Shashkov. 1983. Polysaccharides of algae. XXXIII. Isolation and ${ }^{13} \mathrm{C}-\mathrm{NMR}$ spectral study of some new gel-forming polysaccharides from Japan Sea red seaweeds. Bot. Mar. 26: 285-294.

Usov, A. I., S. V. Yarotsky and A. S. Shashkov. $1980 .{ }^{13}$ CNMR spectroscopy of red algal galactans. Biopolymers 19: 977-990. 